\title{
Attending to Difference in Indigenous People's Experiences of Cyberbullying: Toward a Research Agenda
}

\author{
Bronwyn Carlson and Ryan Frazer
}

\begin{abstract}
Broadly understood as repeated, intentional, and aggressive behaviors facilitated by digital technologies, cyberbullying has been identified as a significant public health concern in Australia. However, there have been critical debates about the theoretical and methodological assumptions of cyberbullying research. On the whole, this research has demonstrated an aversion to accounting for context, difference, and complexity. This insensitivity to difference is evident in the absence of nuanced accounts of Indigenous people's experiences of cyberbullying. In this chapter, we extend recent critiques of dominant approaches to cyberbullying research and argue for novel theoretical and methodological engagements with Indigenous people's experiences of cyberbullying. We review a range of literature that unpacks the many ways that social, cultural, and political life is different for Indigenous peoples. More specifically, we demonstrate there are good reasons to assume that online conflict is different for Indigenous peoples, due to diverse cultural practices and the broader political context of settler-colonialism. We argue that the standardization of scholarly approaches to cyberbullying is delimiting its ability to attend to social difference in online conflict, and we join calls for more theoretically rigorous, targeted, difference-sensitive studies into bullying.
\end{abstract}

Keywords: Indigenous; cyberbullying; social media; bullying; technology; violence

The Emerald International Handbook of Technology-Facilitated Violence and Abuse, 145-163 Copyright (c) 2021 Bronwyn Carlson and Ryan Frazer

Published by Emerald Publishing Limited. This chapter is published under the Creative

Commons Attribution (CC BY 4.0) licence. Anyone may reproduce, distribute, translate and create derivative works of these chapters (for both commercial and non-commercial purposes), subject to full attribution to the original publication and authors. The full terms of this licence may be seen at http://creativecommons.org/licences/by/4.0/legalcode.

doi:10.1108/978-1-83982-848-520211008 


\section{Introduction}

While new social technologies bring many benefits, they also "offer powerful, yet potentially damaging ways for young people to communicate and respond" (Nilan, Burgess, Hobbs, Threadgold, \& Alexander, 2015, p. 2). Broadly understood as repeated, intentional aggressive behaviors facilitated by digital technology platforms, cyberbullying has emerged as one of the most prominent forms of digitally mediated harm. While often considered an extension of "traditional" forms of schoolyard bullying, cyberbullying has attracted additional concern because of the unique affordances of digital technologies. For example, in the online context, bullying can be enacted anonymously, producing a "disinhibition effect" on perpetrators (Walker, Craven, \& Tokunga, 2013); it has been described as "non-stop bullying", in that it can pervade the previously "safe space" of the home (Mishna, Saini, \& Solomon, 2009, p. 1224); and it can attract much larger audiences through connecting with extensive online networks.

Cyberbullying has recently been identified as a significant public health concern in Australia. A major 2014 report for the Australian Government Department of Communications concluded that some $20 \%$ of 8 -17-year-olds experienced cyberbullying in the previous year (Spears, Keeley, Bates, \& Katz, 2014, p. 2). A report by youth health organization ReachOut Australia (2018) found 380,000 young Australians were victims of cyberbullying in 2018. And a recent national survey found that $39 \%$ of Australians have experienced some form of cyber-hatred and violence, and that it has cost the Australian economy an estimated $\$ 3.7$ billion (Australia Institute, 2019). Cyberbullying has been linked to a range of negative health outcomes, most seriously in the forms of depression, anxiety, and suicide ideation (Shohoudi Mojdehi, Leduc, Shohoudi Mojdehi, \& Talwar, 2019). There are also significant social consequences, with victims and perpetrators being more likely to truant school, take leave from employment, and experience social estrangement more generally. Accordingly, cyberbullying has attracted significant attention from researchers, who have sought to accurately measure the rates, effects, and possible preventative measures of cyberbullying.

Recently, however, there have been critical debates about the theoretical and methodological assumptions of cyberbullying research. On the whole, this research has demonstrated an aversion to accounting for context, difference, and complexity. On one hand, there have been concerns that particular approaches to studying cyberbullying have become standardized and canonized, and their disciplinary histories and theoretical assumptions have become obscured in the process. A central issue has hinged on whether the concept of "cyberbullying" itself requires a clear, unambiguous, and consistently applied definition or whether it is too varied a social phenomenon to be fixed in such a way. On the other hand, cyberbullying researchers have tended to overlook important markers of social difference, generally conducting large-scale quantitative research that assumes a homogeneous, normalized, white subject; or, at best, differentiating participants only by age and binary sex.

This insensitivity to difference is evident in the absence of nuanced accounts of Indigenous people's experiences of cyberbullying, both in Australia and globally (Carlson \& Frazer, 2018b). Internet technologies have been taken up enthusiastically by Indigenous peoples across Australia (Carlson \& Frazer, 2018b). They have 
brought great benefits, such as overcoming difficulties in living across geographically distant communities, sustaining informal networks of care and support, and connecting with crucial knowledge, events, and opportunities. Researchers have shown these technologies are used in highly culturally specific ways, with a clear continuity between offline and online cultures (Carlson \& Frazer, 2015).

However, they also present new dangers to Indigenous people's physical, emotional, and cultural safety. The rapid uptake of mobile technologies has seen, as noted by Indigenous scholar Peter Radoll (2012), "an increase in cyber-safety issues" (p. 11) in Indigenous communities - including exposure to racist violence, identity theft, and appropriation of sensitive cultural knowledge. Significantly, there is also evidence that, like many other minority groups, Indigenous peoples are disproportionately affected by cyberbullying (Kral, 2014, p. 181). Despite this, research to date has largely overlooked Indigenous people's experiences of cyberbullying. The small body of available research specifically on Indigenous cyberbullying - in Canada (Broll, Dunlop, \& Crooks, 2018; Brownlee et al., 2014; Mobin, Feng, \& Neudorf, 2017), the US (Samulski, 2014), and Australia (Carlson \& Frazer, 2018a; Radoll, 2012; Vaarzon-Morel, 2014) - has yielded important insights, particularly in demonstrating that we cannot assume cyberbullying occurs at the same rate, for the same reasons, and with the same impacts, as for non-Indigenous peoples.

In this chapter, we extend recent critiques of dominant approaches to cyberbullying research and argue for novel theoretical and methodological engagements with Indigenous people's experiences of cyberbullying. It is structured in two major sections. In the first section, we unpack some of the major trends in current cyberbullying research, before attending to the growing chorus of critiques from qualitative researchers. We argue that the standardization of scholarly approaches to cyberbullying is delimiting its capacity to attend to social difference in online conflict; and we join calls for more theoretically rigorous, targeted, difference-sensitive studies into bullying.

Following this, in the second section, we review a range of literature that unpacks the many ways in which social, cultural, and political life is different for Indigenous peoples, specifically in relation to social conflict. On the one hand, we argue there are a range of cultural differences that mediate and shape interpersonal interactions, including cultures of kinship, communication, and conflict. On the other hand, we argue that Indigenous people's experiences of being online cannot be meaningfully separated from broader racial politics of settler-colonialism and its manifestation through disadvantage. To be Indigenous online, we argue, is to be already entangled within a violent, conflictual politics - for which research on online conflict has so far failed to account.

Finally, we close by outlining an initial agenda for research on Indigenous people's experiences of cyberbullying. In particular, we argue there are three major blind spots in cyberbullying research: their empirical focus, theoretical framings, and methodological approaches. Understanding cyberbullying as a discursive formation always embedded within a social, cultural, and political milieu, this chapter extends critical approaches to cyberbullying research and advances a politically and culturally nuanced approach to understanding cyberbullying. 


\section{Major Trends in Cyberbullying Research}

\section{Context-Insensitivity in Cyberbullying Research}

Understanding the tensions in cyberbullying research requires an understanding of the academic field's historical and academic roots. To this end, in this first section, we offer a brief overview of the scholarly history of bullying and cyberbullying research, paying attention to its grounding in the field of developmental psychology, before moving on to recent critiques.

Scholarly interest in school bullying first emerged in the 1960s when researchers in Sweden began investigating what was initially called "mobbing" (Olweus, 2013) - broadly understood as repeated schoolyard aggression toward less powerful students. The field expanded significantly over the next few decades, as state and public concern around the possible negative effects of schoolyard bullying intensified. Bullying gradually became accepted as a significant, serious, and widespread public health concern. By and large, bullying research sought to better understand its prevalence and effects and sought to develop effective interventions.

Swedish scholar Dan Olweus has been a central figure in bullying research since the field's establishment. Before Olweus, researchers tended to focus on the broader contextual, group and social factors in bullying (see Canty, Stubbe, Steers, \& Collings, 2016 for this academic history). Drawing on ideas from developmental psychology, however, Olweus's work shifted the focus to individual actors, analyzing their psychological traits and behaviors, and deemphasizing any broader social and cultural context. The aim, for Olweus, was to predict and mitigate pathologically deviant bullying behavior (Canty et al., 2016). Through this work, Olweus (2013) produced the most influential definition of bullying, which is composed of three main criteria: (1) intentional aggressive behavior, (2) that involves an abuse of power, and (3) is repeated over time.

Cyberbullying emerged as a scholarly interest in 2000, where the term became used to describe seemingly new forms of aggressive behavior that were playing out on then-new digital technologies, particularly mobile phones and internet-capable computers. It soon became clear that these technologies had led to an evolution in the nature of peer-to-peer aggression (Hinduja \& Patchin, 2010). At that time, there had been a series of high-profile deaths among teens who had experienced severe bullying through these new social technologies, and these events centered public, media, and state attention on these technologies' capacity to facilitate and proliferate harm on youth.

Researchers were quick to translate Olweus's generic conceptualization of "traditional" bullying into this new online context. Cyberbullying became understood "as a form of bullying, in line with other forms, such as verbal, physical and indirect/relational bullying" (Olweus \& Limber, 2018, p. 141). While there is some disagreement around its exact definition, Kowalski, Giumetti, Schroeder, and Lattanner (2014) note that scholars generally emphasize four main elements: "(1) intentional aggressive behavior that (2) is carried out repeatedly, (3) occurs between a perpetrator and victim who are unequal in power, and (4) occurs 
through electronic technologies" (p. 1109). Over time, a more or less standard typology of cyberbullying forms emerged, including flaming, harassment, imagebased sexual abuse, outing, exclusion, cyberstalking, and impersonation (Campbell, Cross, Spears, \& Slee, 2010; Carlson \& Frazer, 2018a; Henry et al., 2020).

Cyberbullying researchers, predominantly with backgrounds in behavioral psychology, health and education, have largely considered a uniform definition both desirable and necessary. Bauman (2015) argues that "research requires a precise and accepted definition that all can use" (p. 23) - what Olweus and Limber (2018) refer to as "concept validity". For these researchers, more or less universal agreement around what constitutes cyberbullying is necessary if we are to, first, measure the rates of cyberbullying perpetration and victimization; second, map rates of change across time, age, and location; and, third, identify effective interventions. By employing increasingly standardized definitions, these researchers have conducted large scale, quantitative, survey-driven studies that have sought validity, replicability, and comparability in cyberbullying research.

However, as we discuss in the following sections, the fast-growing body of cyberbullying research has also attracted significant criticism. In particular, there are disagreements among scholars about what actually constitutes "cyberbullying" and how it is best conceptualized in research. The gradual standardization of cyberbullying research has left it "typically blind to the relational nuances and complexities that characterize cyberbullying" (Nilan et al., 2015, p. 3). And as we will discuss in the chapter's second major section, this blindness is particularly acute when it comes to understanding cyberbullying toward and among Indigenous peoples.

\section{Critiques of the Dominant Approach}

While researchers have conducted excellent work in understanding the extent and effects of cyberbullying across a range of contexts, more recently, scholars from outside these more quantitative, positivist fields have posed critical questions around the implicit epistemological and ontological assumptions this research has made about what is, in practice, an extremely complex social phenomenon. The dominant approach - grounded in and inflected by the discipline of developmental psychology - has individualized and homogenized cyberbullying and related forms of online aggression, rather than understanding it as something alive and unstable, something that plays out in overlapping social fields, involving often ontologically ambiguous and differently positioned actors. These more critical researchers, generally from the social sciences, have argued that clear, rigid, axiomatized definitions can obscure the actual lived experiences, ideas, and motivations of people implicated in online conflict.

In this section, we outline four significant problems in dominant academic approaches to cyberbullying research, including (1) the problematic influence of its dominant definition, (2) its implicit assumption of cultural universalism, (3) the reproduction of a perpetrator-victim model, and (4) its implicit moral hierarchy. 


\section{The Standardization of Definitions}

Over the last 10 years, a body of research has expressed concerns around "the power of prevailing definitions" of cyberbullying in research (Kofoed \& Staksrud, 2019); a concern that popular definitions have a problematic influence on how researchers, policymakers, and young people themselves approach the issue. Definitions, as Canty et al. (2016) remind us, "are made not born" (p. 48); they have social, cultural, and academic histories that are often obscured through repeated use. Reflecting on the previous decade of research, Canty et al. (2016) argue that:

... consistent a priori application of [Olweus's] definition has created an aura of authority and temporal stability that obscures its origin and development, its disciplinary paradigm and assumption, and evidence that the term "bullying" has multiple meanings and uses. (p. 48)

Kofoed and Staksrud (2019, p. 1007) heed Canty et al.'s (2016) warning and document the strange side effects of "definitional overlearning" in cyberbullying research, which can occur through anti-bullying efforts to educate children about bullying by providing them with existing models and definitions of bullying. This has produced "some puzzling side effects" (Kofoed \& Staksrud, 2019, p. 1011), they observe, such as when students are surveyed and respond by telling researchers their definition is "wrong" because it doesn't match what they've already learnt elsewhere; or when students explain that they aren't "cyberbullying" because they only did it a single time - meaning it doesn't fit the official criteria. Their work demonstrates the ontological and social power definitions can have beyond academic circles, where children are taught the supposedly "right" definition of what constitutes cyberbullying. In these ways, the conventional definition leads to "artificial homogeneity," as Canty et al. (2016, p. 53) explain. Kofoed and Staksrud (2019) suggest current conceptualizations of cyberbullying are "inadequate in addressing the complexities of technologically mediated exclusionary processes" (p. 1007). Real situations, they argue, often exceed conventional understandings.

\section{Difference Blindness and Cultural Imperialism}

Second, by relying on a static, three-/four-pronged definition of bullying, which originated within a western social, cultural, and academic context, research has tended to be blind to important markers of social and cultural difference (BodkinAndrews, O’Rourke, Dillon, Craven, \& Yeung, 2012; Coffin, Larson, \& Cross, 2010). On the one hand, despite indications that minority populations experience higher rates of cyberbullying (Llorent, Ortega-Ruiz, \& Zych, 2016), research has tended to be demographically limited (Broll et al., 2018; Mobin et al., 2017), focusing mainly on white, urban populations, differentiating research participants only by age and (binary) gender (Brownlee et al., 2014; Kowalski et al., 2014; Mobin et al., 2017). Consequently, it has largely overlooked non-majority 
populations, including ethnic, cultural, differently-abled, sexual, gender, and religious minorities. Likewise, demographic variables that cut along socioeconomic, geographical (urban, suburban, rural, etc.) and educational (state, private, religious, etc.) lines have also tended to be entirely overlooked.

Cyberbullying research has also tended to be geographically situated within white, majority world contexts - particularly North America and Europe. As Canty et al. (2016) note, "bullying" is a thoroughly Western concept, and correlates don't necessarily exist in other contexts (Smith, del Barrio, \& Tokunga, 2015). Shohoudi Mojdehi et al.'s (2019) work has shown that there are significant cultural factors and "moral mechanisms" that shape how individuals experience and make sense of various forms of social conflict - such as differences between more "individualist" and more "collectivist" societies. In this context, Schott (2014) has questioned whether a cross-cultural definition of cyberbullying is even possible. By not acknowledging the social and cultural embeddedness of cyberbullying research, there is a danger of cultural imperialism - where an idea is taken and inappropriately imposed upon other cultural contexts (Canty et al., 2016).

\section{Reified Subject Positions}

Third, the dominant model of cyberbullying reifies fixed, individual subject positions. Based on Olweus's influential formulation, bullying is understood as a particular subset of "aggression," which relies on a basic perpetrator-victim binary (Kofoed \& Ringrose, 2012). Kofoed and Ringrose (2012) note that in the vast majority of bullying research, then, there are a standard set of relatively fixed subjects: bully, victim, and bystander.

This reification of a standard, inflexible set of subject positions has major consequences for research and practice. As boyd (2014) explains, "by focusing on the perpetrator and protecting the victim, well-intentioned adults often fail to recognize the complexity of most conflicts" (p. 136). The victim-perpetrator dyad can obscure the more ambiguous and unstable elements of the cyberbullying event, overlooking other actors, practices, ideas, and objects involved. It also assumes the involvement only of individual actors. Bodkin-Andrews, O'Rourke, Dillon, Craven, and Yeung (2012) write that "most conceptualizations of bullying occur at the level of the individual, with little sensitivity to notions of cultural identity, broader community issues, socioeconomic and historical disadvantage or oppression" (p. 7). This individualist approach precludes the possibility of understanding more collective forms of hatred and bullying; including how social forms of hate - racism, sexism, homophobia, transphobia, ableism, and so on can be entangled within particular cyberbullying events.

Consequently, rather than assuming a simple perpetrator-victim binary, smaller, more theoretically robust qualitative studies have shown that there are often many differently-positioned and ambivalently-motivated subjects entangled in the event of online conflict (Marwick \& boyd, 2014). Things are much messier and more ambiguous and complex than quantitative studies tend to acknowledge. 


\section{The Moral Hierarchy}

Finally, as Kofoed and Ringrose (2012) note, there is an implicit moral hierarchy baked into standard bullying analysis. The legacy of developmental psychological thinking in cyberbullying research is apparent in how bullying is understood as an individual pathology. The perpetrator-victim model carries moral assumptions: "if bullying is a subset of aggressive behavior, then bullies are aggressors," explains Schott (2014, p. 25). One set of behaviors is understood as "pathological violence," while much other "everyday cruelty" is considered "normal violence" (Ellwood \& Davies, 2010; Kofoed \& Ringrose, 2012) - and, as Ringrose and Renold (2010) have shown, there are often gendered, racialized, and sexualized aspects to this. There are two key points to be made here.

First, as research has repeatedly demonstrated, there is often a blurring of responsibility in online bullying. In practice, lines of fault and responsibility, the intentions of actors, the existence of violence and abuse are often ambiguous or morally ambivalent (Ellwood \& Davies, 2010). In each actual case, it is often not clear who is the aggressor, who is the victim, and who wields power. Indeed, one of the defining marks of cyberbullying is its affordance of deniability - that it is often unclear who the perpetrator was, who "started" it, and what the intention of each actor was (Nilan et al., 2015). Online anonymity confuses clear culpability through plausible deniability - someone can always say it was someone else, or that they didn't "really" mean to hurt them (Mishna et al., 2009).

Second, and more generally, there needs to be a recognition that interpersonal conflict is often a normal and "healthy" part of sociality (boyd, 2014). Thornberg (2011) encourages researchers to look beyond the supposedly "pathological" behaviors of individuals and to instead try to understand bullying as a complex social phenomenon, involving a range of meanings, forces, desires, and practices. The dominant cyberbullying model precludes more nuanced understandings of how power, blame, intention, and agency are embedded within online conflicts. Rather than automatically assuming "bullies" to be bad, pathological, or even criminal actors, moral assumptions about social behaviors need to be understood and carefully contextualized (Shohoudi Mojdehi et al., 2019).

By and large, there appears to be an aversion to difference, complexity, and context in most cyberbullying research. By only taking into account the demographic variables of age and gender - and ignoring all other contextual factors researchers have tended to produce relatively context-insensitive models of cyberbullying. These largely psychological and sociological studies, often drawing on standardized survey instruments, tend to individualize and homogenize participants, and in doing so, erase the social, cultural, political, and economic contexts in which cyberbullying occurs. The legacy of developmental psychology is one of a standardized, culturally-specific, and context-insensitive model of online conflict. The most critical research outlined above makes clear that there is room for research that thinks differently about cyberbullying, that draws on different understandings of "what counts" as cyberbullying, and is better equipped to attend to difference. 


\section{Considering Context in Indigenous People's Experiences of Cyberbullying}

With a few important exceptions, Indigenous populations have not received adequate attention in cyberbullying research. This is despite a growing body of evidence that Indigenous peoples experience higher rates of cyberbullying across a diverse range of settler-colonial contexts, including Australia (Kral, 2014; Spears et al., 2014), Canada, and the US (Lemstra, Rogers, Thompson, Moraros, \& Tempier, 2011; Samulski, 2014). This is a major shortcoming, as Indigenous peoples constitute a distinct social, cultural, and political population in settler nations, with wide-ranging consequences for how they engage with social media technologies.

In this second major section, we extend the above critiques of cyberbullying research by engaging with work across a range of disciplines - sociology, political economy, media studies, anthropology. Here we build on a literature review we were commissioned to produce by the Aboriginal Health \& Medical Research Council of New South Wales, in which we argue that cyberbullying studies have so far - failed to adequately engage with the cultural and political contexts in which Indigenous people are embedded through online conflict (see Carlson \& Frazer, 2018a). On the one hand, we argue that researchers must acknowledge the importance of different cultural, social, and communicative formations in constituting how conflict arises and what role it plays within communities. On the other, we argue that, in understanding cyberbullying, research must attend to the broader context of settler-colonialism. In short, in this section we unpack some ways researchers can engage with the cultural and political contexts in which Indigenous peoples are embedded to better understand their experiences and meanings of cyberbullying.

Following this, in the chapter's final section, we suggest a number of pathways forward for cyberbullying research. We argue that research specifically on, by, and informed by, the ontological and epistemological frames of Indigenous people is needed, if we are to develop effective, relevant interventions for cyberbullying.

\section{The Cultural Context of Cyberbullying}

Encompassing hundreds of distinct nations and language groups across Australia, Indigenous populations hold myriad value systems, sets of norms, ontologies, and spiritual beliefs. Against western notions of the rational, discretely-bound and self-made individual, Indigenous ways of being and knowing tend to emphasize relations, connections, and collectivist notions of responsibility (Christie, 2005). These social and cultural differences are not set apart from the use of digital technologies but are entangled complexly within them - affecting both how these technologies can be used and what impact they have on Indigenous peoples and communities. While working to change social relations between people, social media technologies also have continuities with traditional communicative 
practices. Srinivasan (2013) notes, for instance, that mobile technologies tend to be "translated, adopted, and shaped as they move locally" - an observation that challenges the dominant "top-down" view of technology production and use (p. 207).

As discussed above, however, the vast majority of cyberbullying research is insensitive to these significant cultural contexts. Instead, by assuming a homogeneous - and generally white - population, research tends to ignore, reduce, and strip away these cultural differences. In this section, we draw on our prior research to point toward two key ways in which cultural difference affects online conflict (Carlson \& Frazer, 2018a). First, we argue that systems of kinship and cultures of communication shape how Indigenous peoples engage with Internet technologies, which in turn affect the cause and mitigation of cyberbullying. Second, we argue that different peoples have different "cultures of conflict", which affect what is considered aggressive or pathological online behaviors. Thus, we argue, "what counts" as cyberbullying behavior should not be taken for granted by researchers.

\section{Cultures of Kinship and Communication}

Despite conflict being an essentially social phenomenon, cyberbullying research seldom recognizes that the use of digital communication technologies, such as social media, is a deeply cultural practice that both extends and alters broader social relations (Brownlee et al., 2014; Carlson \& Frazer, 2018a; Kowalski et al., 2014). Broadly, Indigenous sociality is structured by specific relational forms, including clan membership, kinship structures, skin names, and moiety systems (Carlson \& Frazer, 2018a, p. 14; Kral, 2014). These cultural modes of social relation shape one's place within and responsibility to others, including family, community, country, and knowledge.

These culturally specific forms of social relations have wide-ranging implications for cyberbullying research. First, cultural knowledges and practices directly inform how digital technologies are used. As Christie (2005) writes, "wherever Aboriginal people have their own computers they produce and make use of their own digital objects" (p. 61). In their research on mobile phone use among residents of a remote Aboriginal community, Vaarzon-Morel (2014) shows how the introduction of new communication technologies has both extended and transformed traditional social relations among community members. Our own work on Indigenous people's use of social media likewise reveals that online practices are directly informed by cultural knowledges and values, such as how information around Sorry Business (i.e., rules and responsibilities relating to death and dying) is managed, shared, and contained on Facebook (Carlson \& Frazer, 2015).

Second, new communication technologies can lead to the transformation of traditional modes of communication and sociality (Carlson \& Frazer, 2018a). Kral (2014) notes for instance that uptake of social media can "lead to intergenerational tensions as young people explore new patterns of behavior, and older people come to terms with new cultural challenges" (p. 171). In particular, they note that communities have expressed concerns that social media use has undermined traditional gerontocratic power structures, through which social 
relations are sustained and conflict is mediated. Indeed, as Rennie, Hogan, and Holcombe-James (2016) note, "some remote communities have gone so far as to reject the extension of mobile coverage because of cyber safety concerns" (p. 2).

Third, in contrast to the dominant emphasis on the self-made, atomized "individual" in Western social contexts, many Indigenous communities emphasize more collective and relational forms of selfhood (Carlson \& Frazer, 2018a; Shodoudi Mojhedi et al., 2019). In their report on cyber-safety in remote Indigenous communities, Rennie, Yunkaporta, and Holcombe-James (2018) found that, even regarding online practices, "the individual is subsumed within the social, defined by kinship and clan membership" (p. 11). They found Aboriginal specific notions of privacy often do not correspond with mainstream populations; for instance, sharing mobile devices and mobile accounts was common. As a result, and as we have previously noted, "This more collective notion of the self means that cyberbullying incidents cannot always be considered as an isolated act between discrete individuals" (Carlson \& Frazer, 2018a, p. 15). Instead, conflict online can be already embedded within and a continuation of longstanding acrimonious relations between whole families and communities.

Research on Indigenous youth's experience of "traditional" schoolyard bullying supports this argument. Coffin et al. (2010) show that bullying is not just an interpersonal relation, but is shaped by broader cultural practices and social relations. They argue that bullying is different in an Aboriginal context - motivated by different things (such as jealousy, family obligations), geographically differentiated (coastal and inland children reported different experiences), and bound up in different relations of responsibility. The students in their study often felt compelled to fight for their family - including cousins, distant relatives, and lifetime friends. Emery, Hayes, and Parlet's (1998) work on "racist bullying" likewise found there was strong evidence of in-group loyalty in the face of bullying; with Aboriginal students tending to look out for one another.

This more collective understanding of online conflict stands in contrast to the dominant framing in cyberbullying research, which sees conflict through the highly individualistic lens of the victim-perpetrator binary. Indigenous notions of agency and selfhood, which tend to emphasize relations between and responsibilities toward family, community, clan, and kin, need to be considered if the causes, effects, and mitigating factors of cyberbullying are to be adequately understood in these contexts.

\section{Cultures of Conflict}

As we discuss above, the concept of cyberbullying is deeply contested in recent literatures. There are crucial questions around whether "what counts" as cyberbullying specifically or conflict more broadly can be transplanted from one (predominantly white, Western) context to another. Considering cyberbullying is essentially a social practice, there is good reason to presume it will be socially heterogeneous.

On one hand, what researchers might consider a problematic form of interpersonal conflict, might be understood by others as legitimate and "normal" 
violence. As discussed in our prior work (Carlson \& Frazer, 2018a, p. 15), interpersonal and social conflict is often considered a necessary, normal, and positive component of social relations. In the context of Ngaanyatjarra communities of Western Australia, Kral (2014) notes "public explosions of anger or frustration were a socially acceptable way of releasing tension in the Western Desert that enabled conflict between kin to be resolved... generally through ritualized payback, spearfights or 'yaarlpirri'” (p. 184). In Coffin's (2011) work on remote Aboriginal schools, schoolyard bullying was described by Aboriginal students as "something that Aboriginal people do" (p. 90). Finally, Rennie et al. (2018) suggest that, in Aboriginal communities, "physical conflict can be a reassertion of relatedness, even where it may fail to reinstate social order and may in fact have the opposite effect" (p. 8).

On the other hand, scholars have documented a range of culturally-specific forms of aggression and bullying, of which non-Indigenous researchers may not be aware. For instance, Vaarzon-Morel (2014) documents an escalating conflict between Warlpiri communities in which aggressors "uploaded photographs of deceased relatives of members of the opposite faction and defaced them with vitriolic comments" (p. 252) - a highly offensive practice that broke longstanding taboos around Sorry Business. Rennie et al. (2018) discuss a widespread practice across Aboriginal communities popularly referred to as "swearing," which they define as "almost akin to a curse, an indecent assault that must be answered with vigorous aggression" (p. 10). Finally, in Canada, research by Kentel and McHugh (2015) on Aboriginal people's participation in sport document a practice called "mean mugging," which involved staring at someone in a menacing way, intending to make the person feel bad about themselves.

Against Olweus's assertion that a clear, universal definition of cyberbullying is necessary and desirable, we can't assume that our own notions of conflict will always map neatly onto the peoples we study. Distinctions between "normal" and "pathological" violence are not clear cut, "natural," or universal. Rather, online conflict is always culturally mediated, determined, and normalized. By assuming we already know what cyberbullying and other "pathological violence" looks like, we risk incorrectly including behaviors that communities themselves wouldn't consider a problem, while overlooking forms of bullying that might have significant impacts on the individuals and communities involved.

This work makes clear that responses to, interventions for, and strategies to mitigate cyberbullying cannot be applied homogeneously across cultural groups (Carlson \& Frazer, 2018a, p. 19). There are many differentiating factors that would, in many cases, make mainstream interventions ineffective or inappropriate in the context of Indigenous communities. As Broll et al. (2018) argue, "culturally-relevant programming is essential to meeting the needs of Indigenous adolescents" (p. 72). Likewise, Rennie et al. (2018) suggest that "conflict resolution $[\ldots]$ in remote communities can be provided through traditional structures, by Indigenous organizations, or through mainstream legal services" (p. 30). However, these more context-sensitive approaches to understanding motivations for and mitigation of cyberbullying are precluded by the current dominant approach in research. 


\section{The Political Context of Cyberbullying}

As we have previously noted, "Indigenous peoples occupy a unique political position both among mainstream populations and among other minority groups" in settler states (Carlson \& Frazer, 2018a, p. 17). Most fundamentally, Indigenous peoples have, by definition, experienced colonization. While the vast social, cultural, and economic implications of colonization exceed the scope of this chapter, it is important to acknowledge that colonization comprises a significant part of the context in which Indigenous peoples engage with digital technologies (Carlson \& Frazer, 2018a, p. 17).

In this section, we unpack some of the major political considerations in understanding Indigenous people's experiences of cyberbullying. We argue, first, that researchers must acknowledge the already-existing racial politics that underpin Indigenous-settler relations in Australia and seek to understand how this might instigate, facilitate, and mediate Indigenous peoples' experiences of online conflict. Second, we argue that researchers must attend to how settler power manifests materially through popular discourse, Indigenous disadvantage, and intergenerational trauma (Carlson \& Frazer, 2018a, p. 17).

\section{Settler-Colonialism and the Logic of Elimination}

As we have previously argued (Carlson \& Frazer, 2018a, p. 17), all accounts of bullying recognize it necessarily involves an imbalance and abuse of power. Slonje and Smith (2008), for instance, write that "bullying is a form of abuse that is based on an imbalance of power; it can be defined as a systematic abuse of power" (p. 147). Clearly, issues of power also matter in the context of relations between different ethnic, racial, and social groups. Scholarship from Indigenous studies, postcolonial theory, and settler-colonial studies has carefully analyzed the power relations that sustain settler-colonial societies. Settler-colonial scholar Patrick Wolfe (2006) argues that the political and logical foundation of all settler societies is the settler desire to "eliminate the native": those peoples whose ongoing existence rebukes the settler claim to land. He argues that for the settler state to be seen as right and legitimate, it needs to erase Indigenous people's prior (and therefore superior) claim to sovereignty - through physical, cultural, or epistemological elimination.

Existing cyberbullying research tends to overlook the fact that Indigenous people - in Australia and elsewhere - already live deeply entangled within these broader relations of power. Bodkin-Andrews et al. (2012) note that bullying research has, by and large, failed to engage with issues of race. They argue that racism research "has identified a wider cultural/identity-threat that bullying research ... has largely ignored" (Bodkin-Andrews, 2012, p. 1). Bullying is about power and existing power dynamics between Indigenous and non-Indigenous peoples are likely to affect the frequency and forms of cyberbullying that occur.

While these broader political/power relations might seem far removed from issues of bullying - either offline or online - a growing body of literature has unpacked how Indigenous-settler relations play out in everyday encounters. 
Settler-colonial studies understands colonialism as a continuing force in the present, effected through a range of settler institutions (the justice system, the welfare state, capitalist enterprise) and discursive arrangements that work to frame Indigenous people as the "lesser other."

These racial politics play out across a range of everyday social settings. For instance, racism is widespread in Australian schools, where many Indigenous students face direct and systemic forms of prejudice and discrimination (Emery, Hayes, \& Parlet, 1998). Researchers have found bullying to be motivated by racial, ethnic and cultural differences, what Broll et al. (2018) describe generally as "ethnic bullying." The students in Emery et al.'s (1998) study articulated an understanding of racism "in terms of being devalued or disadvantaged on grounds of their race, color or culture" (p. 45). This work shows that Indigenous people are often targeted for abuse because they are Indigenous.

Additionally, as noted in our previous work (Carlson \& Frazer, 2018a), these broader politics directly affect how victims, parents, and schools respond to bullying. Parents in Coffin et al.'s 2010 study of bullying of Aboriginal high school students explained that "teachers did not listen to Aboriginal students when they told them about bullying or that they did nothing to stop this." Meanwhile, the students in their study often responded by "separat[ing] oneself from non-Aboriginal children and [by being] as 'Aboriginal' as possible" (Coffin et al., 2010, p. 83). In Emery et al.'s (1998) research on bullying against Aboriginal students, they found students rarely told teachers about racist bullying, explaining they didn't seem to take their grievances seriously. "You get suspended if you hit someone," one student explained, "but nothing ever happens when people say racist things" (Emery et al., 1998, p. 54).

A growing body of work has also traced the ways that settler power is extended and racist violence enacted through social media technologies. Social media is a significant point of encounter between Indigenous peoples and settlers. Online, hate groups congregate, share racist materials, and organize attacks on others; Indigenous people are exposed to myriad forms of racist discourse and abuse. In some respects, then, social media can be understood as another avenue through which settler power can be affected and the "logic of elimination" might be realized. For these reasons, online interactions - even between two Indigenous users - are always mediated by broader, racial relations of settler power (Carlson \& Frazer, 2020, p. 6).

Rather than understanding bullying as an individual pathology, a more context-sensitive approach can reveal these broader politics. As qualitative research on schoolyard bullying has shown, bullying is a practice through which a particular social and moral order is being sustained; that is, bullying both constrains and makes possible particular subject positions (Ellwood \& Davies, 2010). As Kofoed and Ringrose (2012) argue, cyberbullying can be understood as "a set of discursive processes where certain subject positions are annulled, and deprived of intelligibility" (p. 8). In this way, the identification of difference, and its punishment through bullying, is involved in the creation and erasure of social categories. Understood in this way, the bullying of Indigenous peoples might be 
linked to the settler project of Indigenous elimination, in which Indigenous subjectivities are policed and deprived of intelligibility.

\section{The Politics of Indigenous Disadvantage}

Consequently, and as we have previously argued, cyberbullying research needs to consider the broader context of the material legacy of settler-colonization in Australia (Carlson \& Frazer, 2018a). Indigenous disadvantage can be understood as "a systemic form of racism that manifests materially" (Carlson \& Frazer, 2018a, p. 18), embedded within and arising from settler policies that removed Indigenous people from their land; stolen Indigenous children from families; suppressed Indigenous cultures, knowledges, and languages; and marginalized Indigenous citizens to the lowest social, educational, and economic rungs of settler society. As Mobin et al. (2017) have argued, in this context, we need to better understand how "intergenerational trauma and the after-effects of colonialism" play out through conflictual peer relations online (p. 479). Coffin et al. (2010), for instance, suggest that bullying behavior is affected by "the wider socioeconomic context which, in this case, has been shaped by centuries of institutional racism toward Aboriginal Australians" (p. 85).

However, the vast majority of cyberbullying research - with its focus on individual, atomized actors - overlooks this significant social and political context. This is particularly troubling, as Broll et al. (2018) argue, that "given the plethora of evidence that colonization and forced assimilation policies have contributed to comparatively poorer mental health among Indigenous peoples" (p. 72). If we are to better attend to the cyberbullying experiences of Indigenous peoples and work toward effective interventions, the very real and significant material consequences of settler policy on Indigenous peoples need to be factored into research.

\section{Toward a Research Agenda}

In this paper, we have approached cyberbullying as a distinct discursive formation in both research and everyday life, which carries with it a set of often problematic built-in assumptions that require interrogation. Considering the shortcomings of standard cyberbullying research outlined in the first half of the chapter, we argue that scholars must move beyond quantitative, "top-down" approaches to research (Nilan et al., 2015), which rely on a static, reductive, moralized perpetratorvictim model that renders research insensitive to difference, context, and ambiguity - an issue that is particularly salient considering the absence of scholarly work on Indigenous people's experiences of cyberbullying.

To address this gap in knowledge, we call for rigorous, exploratory, qualitative research into diverse populations' experiences of cyberbullying. We need, as Thornberg (2011) argues, "theoretical and methodological pluralism" in cyberbullying research. The major strength of qualitative research is that it allows for re-theorizing and re-framing entire fields of study (Ellwood \& Davies, 2010). By taking a more open, experimental and exploratory approach, we can produce 
what Kofoed and Ringrose (2012) describe as "complexity-sensitive knowledge of bullying" (p. 7). Rather than assuming to already know what constitutes bullying and seek only to then measure its prevalence and effects, researchers should ask more expansive questions, such as: what are the forces that lead to a bullying event? What are the social, cultural, material, affective, and historical factors at play? And how are these events mediated by technology, heterogeneous cultural knowledges, values and practices, and broader racial politics?

With this challenge in mind, and to close this chapter, we propose three potential pathways forward.

First, and most fundamentally, cyberbullying research needs to attend more closely to significant markers of social difference. While large-scale studies have produced critical knowledge around rates and effects of cyberbullying, too often they have failed to account for demographic and other social factors outside of age and gender. This "top-down" approach smooths over differences between participants within research populations, subsuming minority experiences within mainstream populations. As we demonstrated in the second half of the chapter, there are good reasons to assume that Indigenous people's understandings and experiences of cyberbullying diverge significantly from non-Indigenous peoples. These differences can only be attended to if they are intentionally approached as distinct research populations.

Second, there is a need to deconstruct and destabilize the standard academic discourse of cyberbullying. One way of approaching this task, as suggested by Canty et al. (2016), is to increase our vocabulary around online conflict. To this end, a range of scholars have mobilized alternative terms to approaching cyberbullying, including "drama" (Marwick \& boyd, 2014) and "adversarial peer relations online" (Nilan et al., 2015, p. 1), or more morally neutral terms such as "networked publics" (boyd, 2014) or "online conflict." Rather than attempting to reduce a complex social phenomenon to something clear and rigid, Marwick and boyd (2014) found a lack of definitional clarity to be analytically illuminating; it increased their capacity to see other forms, effects, and causes of conflictual relations among social media users. The small body of qualitative work on Indigenous peoples' experiences of online conflict suggests there exist distinct, emic concepts already being used by participants to describe their online interactions, such as the "swearing" described by Rennie et al. (2018). A diverse conceptual arsenal will allow researchers to better embrace the messiness, ambiguity, and complexity of online conflict.

Finally, a commitment to "theoretical and methodological pluralism" should include Indigenous approaches to research. Indigenous scholars have developed a rich body of work elaborating Indigenous ontologies, epistemologies, and axiologies within social research - methodological approaches which tend to center the lived experiences and worldviews of Indigenous people themselves, rather than always already assuming they can be accurately captured within Western research paradigms (Moreton-Robinson \& Walter, 2009; Nakata, 2007; Rigney, 1999; Tuiwai Smith, 2013). To this end, Coffin (2011) advocates a culture-centered approach to bullying research: a commitment to theories within the culture, an amplification of alternative voices, and a recognition of cultural context. 


\section{References}

Australia Institute. (2019). Trolls and polls -the economic costs of online harassment and cyberhate. Retrieved from https://www.tai.org.au/content/trolls-and-polls-economic-costs-online-harassment-and-cyberhate. Accessed on March 20, 2020.

Bauman, S. (2015). Why it matters. In S. Bauman, D. Cross, \& J. L. Walker (Eds.), Principles of cyberbullying research: Definitions, measures, and methodology (pp. 23-26). London: Routledge.

Bodkin-Andrews, G. H., O’Rourke, V., Dillon, A., Craven, R. G., \& Yeung, A. S. (2012). Engaging the disengaged?: A longitudinal analysis of the relations between Indigenous and non-Indigenous Australian students' academic self-concept and disengagement. Journal of Cognitive Education and Psychology, 11(2), 179-195.

boyd, d. (2014). It's complicated: The social lives of networked teens. New Haven, CT: Yale University Press.

Broll, R., Dunlop, C., \& Crooks, C. V. (2018). Cyberbullying and internalizing difficulties among Indigenous adolescents in Canada: Beyond the effect of traditional bullying. Journal of Child \& Adolescent Trauma, 11(1), 71-79.

Brownlee, K., Martin, J., Rawana, E., Harper, J., Mercier, M., Neckoway, R., \& Friesen, A. (2014). Bullying behaviour and victimization among aboriginal students within northwestern Ontario. First Peoples Child \& Family Review, 9(1), 38-52.

Campbell, M. A., Cross, d., Spears, B., \& Slee, P. (2010). Cyberbullying: Legal implications for schools (Vol. 118). East Melbourne, VIC: The Centre for Strategic Education.

Canty, J., Stubbe, M., Steers, D., \& Collings, S. (2016). The trouble with bullyingdeconstructing the conventional definition of bullying for a child-centred investigation into children's use of social media. Children \& Society, 30(1), 48-58.

Carlson, B., \& Frazer, R. (2015). "It's like going to a cemetery and lighting a candle": Aboriginal Australians, sorry business and social media. AlterNative: An International Journal of Indigenous Peoples, 11(3), 211-224.

Carlson, B., \& Frazer, R. (2018a). Cyberbullying and Indigenous Australians: A review of the literature. Sydney, NSW: Aboriginal Health and Medical Research Council of New South Wales and Macquarie University.

Carlson, B., \& Frazer, R. (2018b). Social media mob: Being Indigenous online. Sydney, NSW: Macquarie University.

Carlson, B., \& Frazer, R. (2020). The politics of (dis)trust in Indigenous help-seeking. In S. Maddison \& S. Nakata (Eds.), Questioning Indigenous-settler relations: Interdisciplinary perspectives (pp. 87-106). Singapore: Springer Verlag.

Christie, M. (2005). Aboriginal knowledge traditions in digital environments. The Australian Journal of Indigenous Education, 34, 61-66.

Coffin, J. (2011). "Make them stop it": What Aboriginalchildren and youth in Australia are saying about bullying. First Peoples Child \& Family Review, 6(1), 83-98.

Coffin, J., Larson, A., \& Cross, D. (2010). Bullying in an Aboriginal context. The Australian Journal of Indigenous Education, 39(1), 77-87.

Ellwood, C., \& Davies, B. (2010). Violence and the moral order in contemporary schooling: A discursive analysis. Qualitative Research in Psychology, 7(2), 85-98.

Emery, C., Hayes, R., \& Parlet, M. (1998). Bullying of, and retaliation by, Aboriginal students in an Australian urban high school. South Pacific Journal of Psychology, 10(2), 43-59. doi:10.1017/CBO9781107415324.004 
Henry, N., McGlynn, C., Flynn, A., Johnson, K., Powell, A., \& Scott, A. J. (2020). Image-based sexual abuse: A study on the causes and consequences of non-consensual nude or sexual imagery. London, NY: Routledge.

Hinduja, S., \& Patchin, J. W. (2010). Bullying, cyberbullying, and suicide. Archives of Suicide Research, 14(3), 206-221.

Kentel, J. L., \& McHugh, T. L. F. (2015). "Mean mugging": An exploration of young Aboriginal women's experiences of bullying in team sports. Journal of Sport and Exercise Psychology, 37(4), 367-378. doi:10.1123/jsep.2014-0291

Kofoed, J., \& Ringrose, J. (2012). Travelling and sticky affects: Exploring teens and sexualized cyberbullying through a Butlerian-Deleuzian-Guattarian lens. Discourse: Studies in the Cultural Politics of Education, 33(1), 5-20.

Kofoed, J., \& Staksrud, E. (2019). 'We always torment different people, so by definition, we are no bullies': The problem of definitions in cyberbullying research. New Media \& Society, 21(4), 1006-1020.

Kowalski, R. M., Giumetti, G. W., Schroeder, A. N., \& Lattanner, M. R. (2014). Bullying in the digital age: A critical review and meta-analysis of cyberbullying research among youth. Psychological Bulletin, 140(4), 1073.

Kral, I. (2014). Shifting perceptions, shifting identities: Communication technologies and the altered social, cultural and linguistic ecology in a remote Indigenous context. The Australian Journal of Anthropology, 25(2), 171-189.

Lemstra, M., Rogers, M., Thompson, A., Moraros, J., \& Tempier, R. (2011). Prevalence and risk indicators of smoking among on-reserve First Nations youth. Paediatrics and Child Health, 16(10), e71-e77.

Llorent, V. J., Ortega-Ruiz, R., \& Zych, I. (2016). Bullying and cyberbullying in minorities: Are they more vulnerable than the majority group?. Frontiers in Psychology, 7, 1507.

Marwick, A. E., \& boyd, d. (2014). Networked privacy: How teenagers negotiate context in social media. New Media \& Society, 16(7), 1051-1067.

Mishna, F., Saini, M., \& Solomon, S. (2009). Ongoing and online: Children and youth's perceptions of cyber bullying. Children and Youth Services Review, 31(12), $1222-1228$.

Mobin, A., Feng, C. X., \& Neudorf, C. (2017). Cybervictimization among preadolescents in a community-based sample in Canada: Prevalence and predictors. Canadian Journal of Public Health, 108(5-6), e475-e481.

Moreton-Robinson, A., \& Walter, M. (2009). Indigenous methodologies in social research. In Walter, M. (Ed.), Social research methods (pp. 95-109). Oxford: Oxford University Press.

Nakata, M. N. (2007). Disciplining the savages, savaging the disciplines. Canberra: Aboriginal Studies Press.

Nilan, P., Burgess, H., Hobbs, M., Threadgold, S., \& Alexander, W. (2015). Youth, social media, and cyberbullying among Australian youth: "Sick friends." Social Media \& Society, 1(2), 2056305115604848.

Olweus, D. (2013). School bullying: Development and some important challenges. Annual Review of Clinical Psychology, 9, 751-780.

Olweus, D., \& Limber, S. P. (2018). Some problems with cyberbullying research. Current Opinion in Psychology, 19, 139-143.

Radoll, P. (2012). Cyber-safety and Indigenous youth. Indigenous Law Bulletin, 8(12), $11-14$. 
ReachOut. (2018). Cyberbullying a growing public health and safety issue for Australian families. Retrieved from https://about.au.reachout.com/cyberbullyingnd-australian-families/. Accessed on February 16, 2020.

Rennie, E., Hogan, E., \& Holcombe-James, I. (2016). Cyber safety in remote Aboriginal communities and towns: Report. Melbourne, VIC: Digital Ethnography Research Centre, RMIT University.

Rennie, E., Yunkaporta, T., \& Holcombe-James, I. (2018). Cyber safety in remote Aboriginal communities: Final report. Melbourne, VIC: Digital Ethnography Research Centre, RMIT University. Retrieved from https://apo.org.au/sites/default/ files/resource-files/2018-06/apo-nid172076_1.pdf. Accessed on March 20, 2020.

Rigney, L. I. (1999). Internationalization of an Indigenous anticolonial cultural critique of research methodologies: A guide to indigenist research methodology and its principles. Wicazo Sa Review, 14(2), 109-121.

Ringrose, J., \& Renold, E. (2010). Normative cruelties and gender deviants: The performative effects of bully discourses for girls and boys in school. British Educational Research Journal, 36(4), 573-596.

Samulski, E. T. (2014). An exploratory study of cyberbullying among Native American Students at Humboldt State University. Doctoral dissertation, Humboldt State University, Arcata, CA.

Schott, R. M. (2014). The social concept of bullying: Philosophical reflections on definitions. In R. M. Schott \& D. M. Søndergaard (Eds.), School bullying: New theories in context (ebook., pp. 21-46). New York, NY: Cambridge University Press.

Shohoudi Mojdehi, A., Leduc, K., Shohoudi Mojdehi, A., \& Talwar, V. (2019). Examining cross-cultural differences in youth's moral perceptions of cyberbullying. Cyberpsychology, Behavior, and Social Networking, 22(4), 243-248.

Slonje, R., \& Smith, P. K. (2008). Cyberbullying: Another main type of bullying?. Scandinavian Journal of Psychology, 49(2), 147-154.

Smith, P., del Barrio, C., \& Tokunga, R. S. (2015). Definitions of bullying and cyberbullying: How useful are the terms?. In S. Bauman D. Cross, \& J. L. Walker (Eds.), Principles of cyberbullying research: Definitions, measures, and methodology (pp. 23-26). London: Routledge.

Spears, B., Keeley, M., Bates, S., \& Katz, I. (2014). Research on youth exposure to, and management of, cyberbullying incidents in Australia: Part A: Literature review on the estimated prevalence of cyberbullying involving Australian minors. Sydney, NSW: Social Policy Research Centre.

Srinivasan, R. (2013). Re-thinking the cultural codes of new media: The question concerning ontology. New Media and Society, 15(2), 203-223.

Thornberg, R. (2011). 'She's weird!'- the social construction of bullying in school: A review of qualitative research. Children \& Society, 25(4), 258-267.

Tuiwai Smith, L. T. (2013). Decolonizing methodologies: Research and Indigenous peoples. New York, NY: Zed Books Ltd.

Vaarzon-Morel, P. (2014). Pointing the phone: Transforming technologies and social relations among Warlpiri. The Australian Journal of Anthropology, 25(2), 239-255.

Walker, J., Craven, R. G., \& Tokunga, R. S. (2013). Introduction. In S. Bauman, D. Cross, \& J. L. Walker (Eds.), Principles of cyberbullying research: Definitions, measures, and methodology (pp. 3-21). New York, NY: Routledge.

Wolfe, P. (2006). Settler colonialism and the elimination of the native. Journal of Genocide Research, 8(4), 387-409. 